\title{
Silicone-supported Cinchona alkaloid derivatives as insoluble organocatalysts in the enantioselective dimerization of ketenes.
}

\author{
Damiano Cancogni, ${ }^{[a]}$ Alessandro Mandoli, ${ }^{*}[\mathrm{a}]$ Ravindra P. Jumde, ${ }^{[\mathrm{a}]}$ and Dario Pini. ${ }^{[a]}$
}

Keywords: Asymmetric Catalysis / Cinchona Alkaloids / Ketene Dimerization / Organocatalysis / Silicones / Supported Catalysts

A straightforward procedure is presented for the covalent immobilization of ester and silyl ether derivatives of the Cinchona alkaloid 10,11-dihydroquinidine within insoluble cross-linked silicone elastomeric films. The materials prepared by this approach were effective heterogeneous organocatalysts in the asymmetric dimerization of ketenes, providing chiral Weinreb $\beta$ - ketoamides in $28-83 \%$ yield and $79-99 \%$ ee in the course of several recycles. A productivity/enantioselectivity protocol is also proposed for a better assessment of the relative merits of soluble and supported asymmetric catalytic systems towards process intensification. [a] Dipartimento di Chimica e Chimica Industriale, Università di Pisa, and CNR - ICCOM (Section of Pisa), Via Risorgimento 35, 56126, Pisa, Italy

Tel.: (+39)-050-221-9231

Fax: (+39)-050-221-9260

E-mail: alexm@dcci.unipi.it

Supporting information for this article is available on the WWW under http://www.eurjoc.org/ or from the author.

\section{Introduction}

Starting in the early 70's, the increasing use of homogeneous enantioselective catalysis has been accompanied by the development of covalently immobilized analogues. ${ }^{[1]}$ Stemming from the exploration of alternative anchoring strategies, chiral derivatives and support materials, a large number of effective insoluble polymer-bound (IPB) catalysts or ligands are thus known at present to convincingly demonstrate the viability of the approach at the proof-of-concept level and clarify some important design elements required for the attainment of high catalytic activity and enantioselectivity.

Nonetheless, the hesitation to adopt this strategy for practicalscale applications seems still strong. ${ }^{[1 b]}$ Arguably this reluctance is partially dictated by cultural motivations, but it is also reasonable to say that the lack of evidence for decisive practical advantages in the use of the supported catalysts concurs to sustain it. ${ }^{[1 \mathrm{~h}, 2]}$ In this regard, a common concern for most of the disclosed IPB systems is about their preparation, which often appears too complex or poorly efficient for any realistic scale-up planning. Even when this is not the case, the limited efforts put in studying catalyst recycling can be another problem that hampers a clear-cut answer to the question whether the repeated use of IPB systems can actually pay back for their generally more onerous obtainment.

To further complicate this judgment, within some limits the repeated use of an IPB catalyst may have an overall outcome analogous to the reduction of the loading of a homogeneous one, i.e. the increase of the productivity $P$ (defined as the moles of product obtained per mole of catalyst) and the decrease of the $e e$ values. ${ }^{[3]}$ Provided some reduction of the stereochemical purity of the product can be tolerated at the synthesis stage, the use of diminished amounts of the soluble system may then be considered an equally valid option for process intensification, as opposite to the development of supported analogues. Under these circumstances, it is clear that for the field to improve its credibility proper comparison protocols have to be implemented and thoroughly used in this kind of studies.

The general considerations stated above hold true when the specific area of ligands and organocatalysts derived from the Cinchona alkaloids 1-4 (Figure 1) ${ }^{[4]}$ is considered. In fact, by ingeniously exploiting the polyfunctional nature of the alkaloid core and alternative immobilization techniques, a large array of IPB alkaloid architectures have been reported, ${ }^{[1-\mathrm{l}, \mathrm{h}, 3]}$ some of which are summarized in the Figure 2. However, with a few exceptions where the native alkaloids (or simple derivatives thereof) were effectively coupled to commercially available functional resins (e.g. 5 and $\mathbf{6}),{ }^{[5 \mathrm{~d}-\mathrm{f}]}$ the preparation of most of the disclosed materials appears largely unpractical. Typically, this was a consequence of the lengthy reaction schemes and repeated purifications in the synthesis of anchorable alkaloid derivatives (e.g. 10 $)^{[3]}$ or the low immobilization yield and the limited alkaloid loading attained in the actual immobilization step (e.g. 8 and 9). ${ }^{[5 a, 5 c]}$ As pointed out also by Kacprzak and Lindner in a work on Cinchona alkaloid-based chiral stationary phases, ${ }^{[6]}$ the development of IPB alkaloid derivatives for practical uses would therefore require a stronger emphasis on the efficiency of their preparation.<smiles>COc1ccc2nccc(C(O)[C@@H](O)C3CC4CCC(C4)C3)c2c1</smiles>

1 (8R,9S): QD-H 2 (8S,9R): QN-H<smiles>COc1ccc2nccc([C@@H](O)C3CC4CCC(C3)N4C)c2c1</smiles>

3 (8R,9S): DHQD-H

Figure 1. Structure, acronyms, and numbering scheme of the Cinchona alkaloids discussed in this work. 
<smiles>C=CC1CC2CCN(Cc3ccc(-c4ccccc4)cc3)C1C(O)C2c1ccnc2ccc(OC)cc12</smiles>

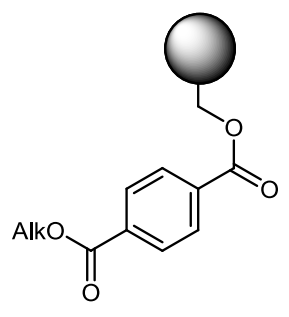

6

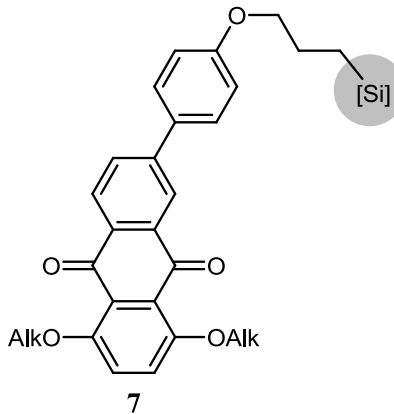

siliceous support<smiles>COc1ccc2nccc([C@@H](O)C3CC4CCC(C3)N4CCSCCC[SiH3])c2c1</smiles>

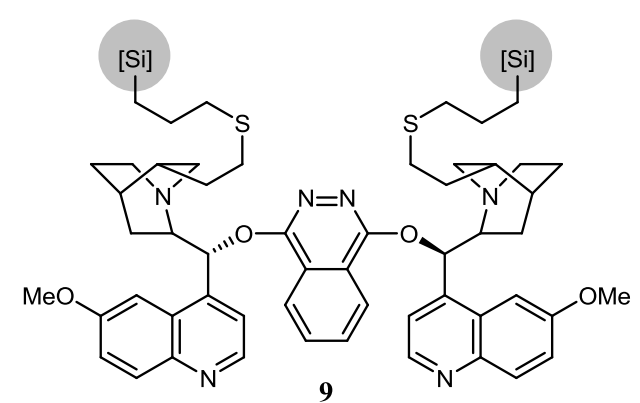

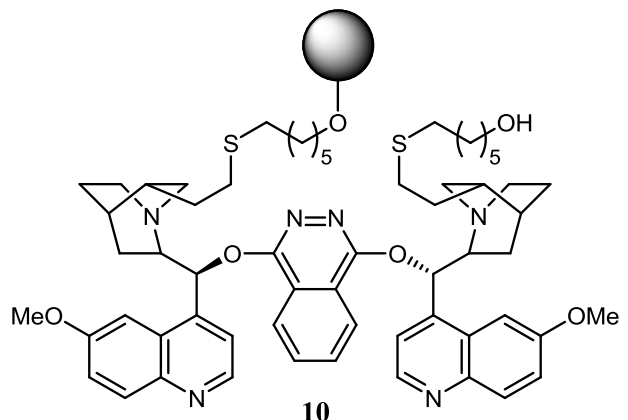<smiles>Oc1cc(CCCCc2cn(CC3CCCCCC3)nn2)c(O[Na])nn1</smiles>

Figure 2. Typical anchoring positions for Cinchona alkaloid derivatives and selected IPB material architectures (AlkO = QD, QN, DHQD, or DHQN - see Figure 1).

With this aim we recently developed a new protocol for the access to the dimeric alkaloid derivatives linked to gel-type or macroporous polystyrene supports. ${ }^{[5 \mathrm{~g}]}$ That strategy proved highly effective in many respects, including a scalable preparation of the anchorable derivatives and their efficient coupling to preformed resins in a click-chemistry step. Moreover, the resulting materials 11 turned out to be remarkable organocatalysts in the asymmetric dimerization of ketenes described by Calter and co-workers, ${ }^{[7]}$ affording chiral Weinreb $\beta$-ketoamides in $90-97 \%$ ee in the course of 20 reaction cycles. ${ }^{[\mathrm{g}]}$

Nonetheless, the relatively complex structure of $\mathbf{1 1}$ appears not strictly required for the aforementioned reaction because simpler monomeric 9- $O$ alkaloid derivatives, like the propionate esters (Prop) and the trimethylsilyl (TMS) or tert-butyldimethylsilyl (TBDMS) ethers are equally effective organocatalysts. ${ }^{[7, b, 7 f]}$ In addition, whilst polystyrene resins provide the IPB systems in the form of reasonably robust beads, in the case of immobilized bisoxazoline (Box) ligands $\mathrm{we}^{[8]}$ and the group of Nagashima ${ }^{[9]}$ recently found that the switch to cross-linked silicone supports could present some advantages in terms of handling and catalytic performances.

These considerations prompted us to investigate the covalent immobilization of monomeric 9- $O$ derivatives of 10,11 dihydroquinidine (DHQD-H, 3) within insoluble elastomeric silicone films and their use as organocatalysts in the heterogeneous asymmetric dimerization of ketenes. In the course of this study, the problem of comparing the IPB systems with their soluble counterpart was also addressed, leading to the results presented in the following sections.

\section{Results and Discussion}

Preparation of anchorable DHQD derivatives
Cinchona alkaloids had been coupled to linear poly(methylhydrosiloxane) (PMHS) by the groups of Siegel and Bergbreiter. ${ }^{[10]}$ However, the main goal of these investigations was the preparation of soluble materials, some of which were obtained by direct hydrosilylation of the alkaloid's 10,11-double bond. By contrast, the cross-linked structure of the IPB materials explored in the present work suggested the introduction of a spacer group between the chiral moiety and the terminal alkene-anchoring site. Similarly to Siegel and co-workers, ${ }^{[10 a]}$ synthetic efficiency considerations suggested to embed it into the 9-O substituent. This led to the design of the three DHQD derivatives 16, 17, and 18, which can be considered the anchorable variants of the soluble Prop, TMS, or TBDMS organocatalysts noted above.

The synthesis of the silyl ethers $\mathbf{1 7}$ and $\mathbf{1 8}$ required the initial preparation of the corresponding chlorosilanes 13 and 15, achieved as depicted in the Scheme 1 by reacting dichlorodimethylsilane with the Grignard reagents obtained from the halides 12 or 14. ${ }^{[11]}$ Besides using cheap chemicals, a practical advantage of this route was that pure-enough 13, 14, and 15 could be obtained in acceptable (yet not optimized) yields by a simple and scalable procedure that involved high-vacuum distillation as the purification technique.

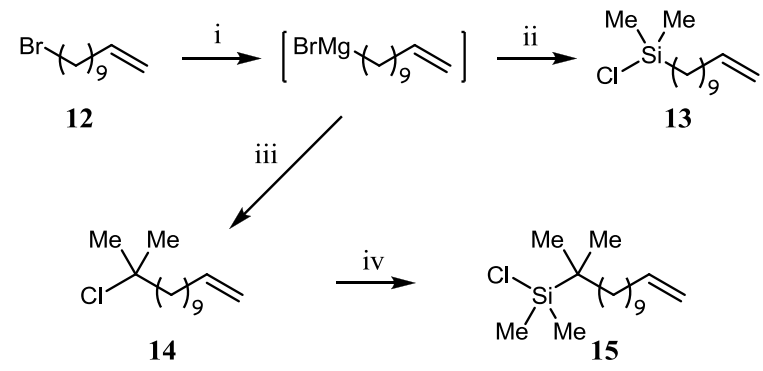

Scheme 1. Synthesis of the chlorosilanes 13 and 15. Reagents and conditions: (i) $\mathrm{Mg}, \mathrm{Et}_{2} \mathrm{O}$; (ii) $\mathrm{Me}_{2} \mathrm{SiCl}_{2}, \mathrm{THF}, 50 \%$ from 12; (iii)(a) acetone, $\mathrm{Et}_{2} \mathrm{O}$; (b) $37 \% \mathrm{HCl}, \mathrm{ZnCl}_{2}, 50 \%$ from 12; (iv)(a) $\mathrm{Mg}, \mathrm{THF}, 70^{\circ} \mathrm{C}$; (b) $\mathrm{Me}_{2} \mathrm{SiCl}_{2}$, cat. $\mathrm{CuCN}, \mathrm{THF}, 43 \%$ from 14 . 


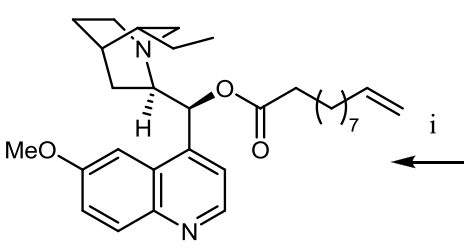

16

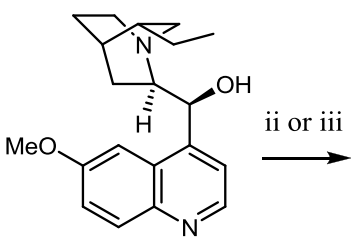

3

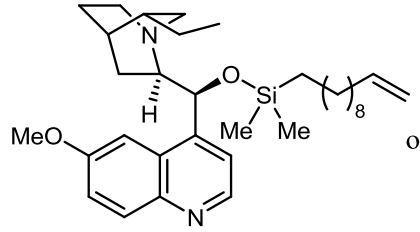

17

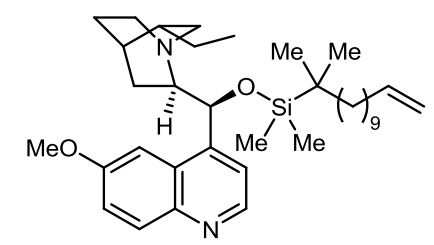

18

Scheme 2. Synthesis of the anchorable alkaloid derivatives 16, 17, and 18. Reagents and conditions: (i) 1.3 equiv. 10 -undecenoyl chloride, $\mathrm{CH}_{2} \mathrm{Cl}_{2}$, r.t., $48 \mathrm{~h}$, $75 \%$; (ii) 1.3 equiv. 13, 2 equiv. $\mathrm{Et}_{3} \mathrm{~N}, 30$ mol\% DMAP, DMF, r.t., 48 h, 62\%; (iii) 1.3 equiv. 15, 4.5 equiv. Et $\mathrm{t}_{3} \mathrm{~N}, 10$ mol\% DMAP, DMF, r.t., 72 h, $53 \%$.

Next, the synthesis of the anchorable alkaloid derivatives was carried out as shown in the Scheme 2. For the preparation of the 9$O$ undecenoic ester $\mathbf{1 6}$ a modification of the reported procedure for the analogous Prop derivative was used, ${ }^{[7 a]}$ consisting in the reaction of DHQD (3) with commercially available 10-undecenoyl chloride without any additional base. Similarly, 17 and 18 were prepared by reacting 3 with the chlorosilanes 13 and 15 under the conditions reported for the synthesis of the corresponding TMS and TBDMS ethers. ${ }^{[7 a, 12]}$ After chromatographic purification, fractions of 16, 17, and 18 were obtained in fair to good yields, as clear oils that gave a single spot by TLC. The identities of the three alkaloid derivatives were confirmed by electrospray mass spectrometry and by ${ }^{1} \mathrm{H}$ and ${ }^{13} \mathrm{C}$ NMR. In the case of the known ester 16 the spectroscopic constants proved identical to the published ones, ${ }^{[10 \mathrm{a}]}$ including the occurrence of single sets of sharp resonances in both ${ }^{1} \mathrm{H}$ and ${ }^{13} \mathrm{C}$ NMR. On the contrary, the spectra of the new silyl ether 18 were somewhat more complicated, showing two distinct sets of sharp resonances (ratio $76: 24$ ) in ${ }^{1} \mathrm{H}$ and ${ }^{13} \mathrm{C}$ NMR. Given the sample homogeneity, these observations are best explained as a consequence of the restricted rotation around the $\mathrm{C}_{9-}$ $\mathrm{O}$ and $\mathrm{O}-\mathrm{Si}$ bonds of the hindered derivative 18. Interestingly, similar conclusions were reported for other Cinchona alkaloid TBDMS silylethers, which showed a $\sim 75: 25$ ratio of rotamers by ${ }^{1} \mathrm{H}$ NMR. ${ }^{[12]}$

\section{Preparation of DHQD derivatives in cross-linked silicone elastomeric films}

Previous work in the immobilization of chelating Box ligands within elastomeric silicone films demonstrated the advantage of using highly active nanostructured solvated Pt catalysts in the hydrosilylation step. ${ }^{[8]}$ However, the reduced coordinating ability of the monomeric derivatives 16-18, as well as literature precedents, ${ }^{[10 a]}$ suggested that commercial Pt catalysts could also fit the needs of the present work.

To test this hypothesis, 17 was reacted in $\mathrm{C}_{6} \mathrm{D}_{6}$ with PMHS ( $\mathrm{x}=$ $\mathrm{y} \sim 6$, see Scheme 3), in the presence of a small amount of the commercial Karstedt catalyst (Si-H : $17: \mathrm{Pt}=1000: 200: 1)$. After $5 \mathrm{~h}$ at $50{ }^{\circ} \mathrm{C},{ }^{1} \mathrm{H}$ and ${ }^{13} \mathrm{C}$ NMR indicated a complete conversion, as evidenced by the disappearance of the olefin and allyl signals of the alkaloid's side chain. In addition, the spectra of the final solution showed neither degradation of the alkaloid core, nor significant isomerisation of the terminal double bond of $\mathbf{1 7}$ to the hydrosilylation-refractory internal positions. ${ }^{[13]}$ The covalent linking of the chiral unit to PMHS was also confirmed by the growth in the ${ }^{13} \mathrm{C}$ spectrum of two broad resonances at 23.4 and $17.9 \mathrm{ppm}$ that, by comparison with literature values, ${ }^{[14]}$ identified the $\mathrm{CH}_{2} \mathrm{CH}_{2} \mathrm{Si}$ fragment of the polymer-bound alkaloid.

Whilst these initial experiments proved useful in validating the chemistry involved in the anchoring procedure, gelation and some gas evolution was noticed in the $\mathrm{C}_{6} \mathrm{D}_{6}$ sample shortly after the end of the NMR measurements. The poor solubility of the gelled material hampered a detailed investigation of the phenomenon, which was nonetheless likely to arise from side-reactions of the excess Si-H units of PMHS after the complete conversion of the vinyl groups of 17. ${ }^{[13,15]}$

Because the observed phase separation made unfeasible the preparation of uniform elastomeric films by the previously developed two-step approach, ${ }^{[8]}$ the investigation of a single-step procedure was decided instead. Toluene solutions of 16,17 , or 18 , PMHS, low and high molecular-weight divinyl-terminated silicones (PDMS-DV lw and hw, respectively) ${ }^{[8]}$ and the Karstedt catalyst were hence gently heated overnight under air, in a PTFElined vessel (Scheme 3).

\section{6,17 , or 18}
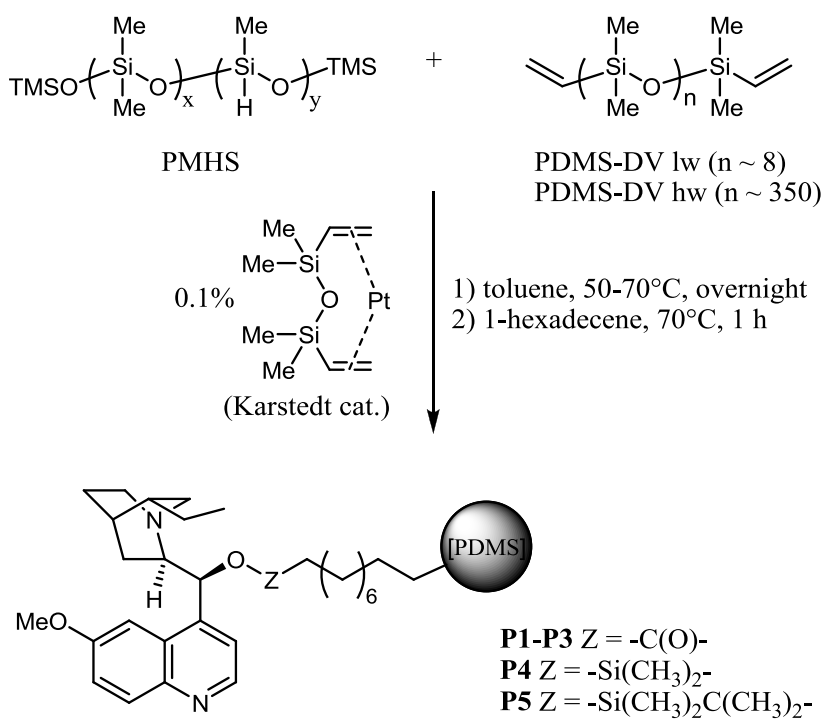

Scheme 3. Preparation of the IPB alkaloid derivatives P1-P5.

Table 1. Feed composition and characterization data for P1-P5

\begin{tabular}{|c|c|c|c|c|}
\hline \multicolumn{3}{|c|}{ Feed } & \multicolumn{2}{|c|}{ Elastomeric film } \\
\hline $\begin{array}{l}\text { Alkaloid } \\
\text { deriv. }\end{array}$ & $\begin{array}{l}\text { PMHS } \\
{[x: y]}\end{array}$ & Composition $^{[a]}$ & & $\begin{array}{c}\text { Loading } \\
{\left[\mathrm{mmol} \mathrm{g}^{-1}\right]^{[b]}}\end{array}$ \\
\hline 16 & $6: 6$ & $3: 1: 1(25)$ & $\mathbf{P 1}$ & $0.28 \pm 0.007$ \\
\hline 16 & $6: 6$ & $5: 1: 2(30)$ & $\mathbf{P 2}$ & $0.19 \pm 0.004$ \\
\hline 16 & $0: 26$ & $3: 1: 1(35)$ & P3 & $0.57 \pm 0.004$ \\
\hline 17 & $6: 6$ & $3: 1: 1(25)$ & P4 & $0.24 \pm 0.007$ \\
\hline 18 & $6: 6$ & $3: 1: 1(25)$ & P5 & $0.26 \pm 0.04$ \\
\hline
\end{tabular}

[a] Molar ratio Si-H : alkaloid deriv. : PDMS-DV lw (in parentheses wt\% of PDMS-DV hw in the feed). [b] Alkaloid content from nitrogen elemental analysis (average of two determinations). 
The evaporation of the solvent resulted in the casting of robust cross-linked films that were swollen with an excess of 1hexadecene in toluene and heated again to cap any residual $\mathrm{Si}-\mathrm{H}$ group. Continuous extraction with THF and $\mathrm{CH}_{2} \mathrm{Cl}_{2}$ and drying under vacuum afforded the five material P1-P5 (Table 1) that were characterized by IR (Supporting Information) and microanalytical determination of the nitrogen content. The former technique ruled out significant amounts of unreacted $\mathrm{Si}-\mathrm{H}$ and $\mathrm{C}=\mathrm{C}$ units as demonstrated by the lack of appreciable absorptions at 2280-2400 $\mathrm{cm}^{-1}$ and $\sim 1600 \mathrm{~cm}^{-1}$, respectively, in all of the IPB materials. ${ }^{[16]}$ In the case of $\mathbf{P 1}, \mathbf{P 2}$, and $\mathbf{P 3}$ the incorporation of the ester derivative in the elastomeric network was also confirmed by the presence of a weak carbonyl stretching around $1748 \mathrm{~cm}^{-1}$. IR spectroscopy proved less informative for P4 and P5 due to the lack of strong bands of the alkaloid and side-chain fragments in the spectral regions not obscured by the polysiloxane backbone. Nonetheless, nitrogen elemental analysis demonstrated a substantial incorporation of the chiral derivative for all of the prepared materials, with alkaloid contents ranging from 0.19 to $0.57 \mathrm{mmol} \mathrm{g}$

${ }^{1}$ (Table 1). The comparison of the experimental loadings with the values calculated from the feed compositions revealed that the functionalization degree of the recovered films P1-P5 was more sensitive to the Si-H content of the PMHS precursor and $\mathrm{Si}-\mathrm{H}$ : alkaloid ratio than to the actual nature of the chiral derivative. Indeed, the use of different soluble precursors $(16,17$, or 18) but the same Si-H : alkaloid molar ratio (3: 1) and PMHS copolymer $(\mathrm{x}=\mathrm{y} \sim 6)$ in the preparation of $\mathbf{P 1}, \mathbf{P 4}$, and $\mathbf{P 5}$ resulted in rather similar anchoring levels $(60,55$, and $59 \%$ of the corresponding theoretical values, respectively). On the contrary, the increase of the $\mathrm{Si}-\mathrm{H}$ : alkaloid ratio to $5: 1$ or the switch to the use of pure methylhydrosiloxane homopolymer $(\mathrm{x}=0, \mathrm{y} \sim 26)$ caused a significant rise of the incorporation of the same chiral derivative (16) in the materials P2 and P3 (76 and 129\% of the theoretical, respectively).

Clearly, the attainment of a higher than expected loading for the latter was due to a significantly reduced incorporation of polysiloxane components in the film. This conclusion was confirmed by the mass recovery of purified insoluble materials that proved much lower for $\mathbf{P 3}$ than for the other cross-linked films ( $22 \%$ vs. $74-90 \%$ of the feed weight, respectively). Together with the trends in the functionalization degree, discussed above, these results affected also the absolute immobilization yield of the alkaloid precursor 16, 17, or $\mathbf{1 8}$ that was $28 \%$ in the case of $\mathbf{P 3}$ and $45-56 \%$ for the other IPB systems P1, P2, P4, or P5.

\section{Homogeneous asymmetric ketene dimerization}

To test the suitability of the new chiral derivatives of this work in the asymmetric dimerization of ketenes, some homogeneous catalysis experiments were carried out first. With this aim, the soluble compounds 16, 17, and 18 were employed under the conditions described by Calter and co-workers for the in situ generation of ketenes from the acid chlorides 19a-c and one-pot opening of the intermediate $\beta$-lactone dimers 20a-c to the corresponding Weinreb amides 21a-c (see also the Supporting Information). ${ }^{[7 \mathrm{f}]}$

In the dimerization of methylketene from 19a (Table 2, entries 1 , 4, and 5) all of the three modified catalysts $\mathbf{1 6}, \mathbf{1 7}$, and $\mathbf{1 8}$ appeared capable of providing 21 a with $94-98 \%$ ee, albeit in slightly reduced yields $(56-64 \%)$ with respect to the published ones $(65-79 \%) .{ }^{[7 f]}$ Interestingly, in the case of $\mathbf{1 7}$ the enantioselectivity level matched that reported for the corresponding TMS ether of quinidine (TMS1), thus suggesting that neither the introduction of the longer side chain in the silyl group nor the saturation of the alkaloid 10,11double bond had major impact on the reaction stereoselectivity.

A similar comparison for the other two organocatalysts is less straightforward because published data refer to the use of Prop or TBDMS derivatives of the quinine pseudoenantiomer (2) that afford $69 \%$ ee and $94 \%$ ee, respectively, in the dimerization of the ketene from the acid chloride $19 \mathbf{a}^{[7 \mathrm{f}]}$

Table 2. Homogeneous and heterogeneous asymmetric catalytic dimerization of ketenes from acid chlorides.

\begin{tabular}{|c|c|c|c|c|c|c|c|}
\hline & & $\underset{2, \text { r.t., } t_{1}}{\stackrel{(1 \text { equiv. })}{(5 \mathrm{~mol} \%)}}$ & $\gamma$ & $\begin{array}{r}\begin{array}{r}\mathrm{HN} \\
\text { 2-pyrid }\end{array} \\
\mathrm{CH}_{2}\end{array}$ & $1 \%)$ & & $\begin{array}{l}=\mathrm{Me} \\
=\mathrm{Et} \\
=i-\mathrm{Pr}\end{array}$ \\
\hline & & & 0a-c & & & 1a-c & \\
\hline Run & Catalyst & Acid chloride & $t_{l}[\mathrm{~h}]$ & $t_{2}[\mathrm{~h}]$ & Product & Yield [\%] ${ }^{[\mathrm{a}]}$ & $\operatorname{Ee}[\%]^{[b]}$ \\
\hline 1 & 16 & $19 a$ & 6 & 2 & $21 a$ & 57 & 94 \\
\hline 2 & 16 & 19b & 6 & 2 & $21 b$ & 83 & 96 \\
\hline 3 & 16 & $19 \mathrm{c}$ & 24 & 24 & 21c & 52 & 97 \\
\hline 4 & 17 & $19 a$ & 6 & 2 & $21 a$ & 56 & 97 \\
\hline 5 & 18 & $19 a$ & 6 & 2 & $21 a$ & 64 & 98 \\
\hline 6 & P1 & $19 a$ & 6 & 2 & $21 \mathrm{a}$ & 58 & 94 \\
\hline 7 & P1 & $19 b$ & 6 & 2 & $21 b$ & 88 & 96 \\
\hline 8 & P1 & $19 \mathrm{c}$ & 24 & 24 & 21c & 79 & 95 \\
\hline 9 & P2 & $19 a$ & 6 & 2 & $21 a$ & 60 & 95 \\
\hline 10 & P3 & $19 a$ & 6 & 2 & $21 a$ & 64 & 93 \\
\hline 11 & P4 & $19 a$ & 6 & 2 & $21 a$ & 53 & 94 \\
\hline 12 & P4 & $19 b$ & 6 & 2 & $21 b$ & 69 & 99 \\
\hline 13 & P4 & $19 \mathrm{c}$ & 24 & 24 & $21 \mathrm{c}$ & 67 & 99 \\
\hline 14 & P5 & $19 a$ & 6 & 2 & $21 a$ & 57 & 98 \\
\hline 15 & P5 & 19b & 6 & 2 & $21 b$ & 62 & 95 \\
\hline 16 & P5 & $19 \mathrm{c}$ & 24 & 24 & 21c & 50 & 96 \\
\hline
\end{tabular}

[a] After isolation by flash chromatography. [b] By HPLC with chiral stationary phases; the prevailing enantiomer had $(S)$ configuration. 


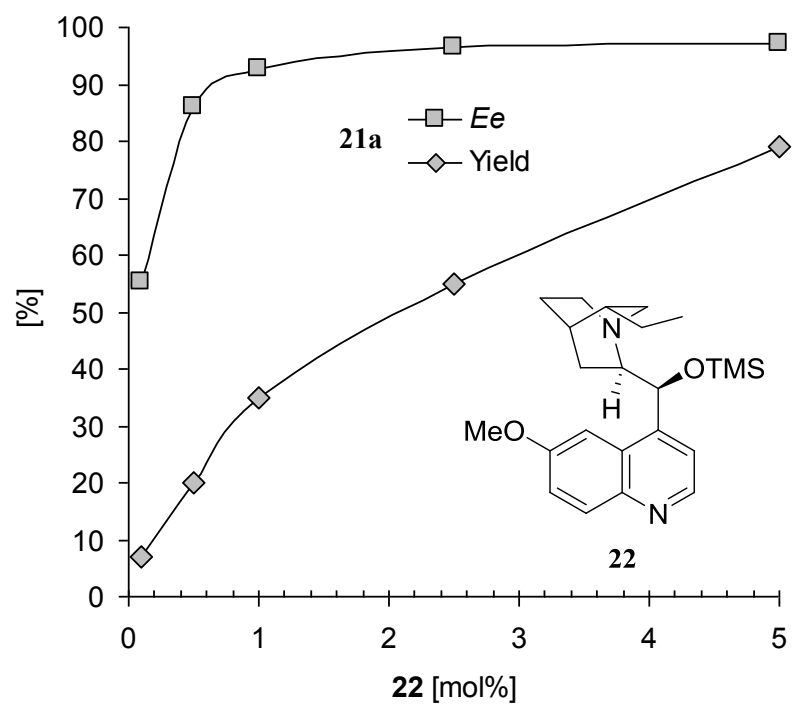

Figure 3. Asymmetric dimerization of methylketene in the presence of the soluble derivative 22 (5 mol\% data are for TMS-2, from ref. ${ }^{[7 f]}$; for the other conditions see Table 2 ).

Nonetheless, we were pleased to find that $\mathbf{1 6}$ and $\mathbf{1 8}$ could provide $94 \%$ ee and $98 \%$ ee, respectively, in the same reaction (Table 2, entries 1 and 5). Besides witnessing the strong influence of the alkaloid peripheral positions, including the diastereomeric relationship between the chiral cores, ${ }^{[17]}$ the practical implication of these findings was the possibility of attaining synthetically useful $e e$ values in the quinidine series by the use of the simple ester derivative 16. This conclusion was corroborated by two further runs with 16 in the dimerization of homologous ketenes from $\mathbf{1 9 b}$ and $19 \mathrm{c}$, which led to the corresponding Weinreb amides with 96$97 \%$ ee (Table 2, entries 2 and 3).

For a better comparison of the productivity of homogeneous and heterogeneous catalytic systems (vide infra), a series of experiments were also carried out with variable amounts of the soluble TMS ether 22 (Figure 3). The results of these tests revealed that the reaction of methylketene could tolerate a twofold reduction of the catalyst loading below the literature conditions $(5 \mathrm{~mol} \%)^{[7 \mathrm{f}]}$ without any major erosion of the ee of the product 21a. However, further lowering of the alkaloid amount resulted in a rapid degradation of performances, with an abrupt decrease of isolated yields and ee values when the loading was reduced below the 1 $\mathrm{mol} \%$ level.

\section{Heterogeneous asymmetric ketene dimerization}

The heterogeneous catalysis experiments were carried out with 5 mol\% of the IPB derivatives P1-P5. The conditions were the same as described above for the homogeneous runs with the only variant that, due to the lack of an active role of the alkaloid units in the opening of the chiral $\beta$-lactone intermediate, ${ }^{[7 b]}$ the successive reaction steps were performed in two distinct vessels. As detailed elsewhere, ${ }^{[5 \mathrm{~g}]}$ after stirring for the time $t_{l}$ the solution containing the chiral dimer 20a-c was separated from the organocatalyst film by siphoning, treated with $\mathrm{N}, \mathrm{O}$-dimethylhydroxylamine and 2pyridone and then stirred again for the time $t_{2}$ to give the final product 21a-c. Standard filtration experiments were carried out concurrently (Supporting Information) and ruled out a significant homogeneous contribution to catalysis from species leached into the solution.
Screening of P1-P5 in the reaction of propionyl chloride (19a) showed that all of the silicone-supported derivatives could effectively promote the asymmetric dimerization of methylketene (Table 2, entries 6, 9-10, and 14). Despite the insoluble nature of the catalytic system, the isolated yields of the chiral dipropionate product 21a proved satisfactory and comparable to those afforded by the soluble compounds 16-18 after identical $t_{1}$ and $t_{2}$ reaction times. Excellent results were also achieved in terms of enantioselectivity, with ee values as high as $93-98 \%$. As expected on the basis of the preliminary homogeneous runs, the stereochemical efficiency of the supported organocatalysts turned out to be somewhat dependant on the structure of the immobilized alkaloid derivative, reaching optimal results in the case of the TBDMS-like material P5 (Table 2, entry 14). On the contrary, different film composition and catalysts loading appeared to have a minor impact on the catalytic properties, as proved by the rather uniform performances of the materials containing the same undecenoyl ester derivative within the variable polymer architecture of P1-P3 (Table 2, entries 6, 9, and 10).

The promising results in the asymmetric dimerization of methylketene were confirmed by using P1, P4, and P5 in the reaction of the homologues from the acid chlorides $19 b$ and $19 c$ (Table 2, entries 7, 8, 12, 13, 15, and 16). Also in these cases acceptable yields were obtained under standard conditions together with ee values matching, or slightly surpassing, those afforded by the soluble alkaloid derivatives in this work (Table 2, entries 2 and 3) or from the literature. ${ }^{[7 f]}$

Overall, the covalent immobilization into elastomeric silicone films proved capable of preserving to a large extent the high enantioselectivity and satisfactory activity of the soluble organocatalysts 16-18. Therefore, the cross-linked polysiloxane network of P1-P5 appears well suited for the heterogeneous catalysis of the reaction under exam, with no appreciable impact on the asymmetric induction ability of the supported chiral units and the possibility for the species in solution to access them. Concerning this latter point, it is interesting to note that even if the rate-limiting step in the homogeneous reaction -ketene formationis known to be independent from the alkaloid derivative concentration, ${ }^{[7 \mathrm{f}]}$ the attainment of dimerization products with substantial yields and ee values requires the involvement of the chiral organocatalyst For this reason, the occurrence of critical diffusion problems in the materials P1-P5 appears unlikely.

\section{Catalyst recycling and productivity evaluation}

As already found with Box ligands, ${ }^{[8]}$ the film shape of the materials P1-P5 allowed their prompt separation from the reaction mixture by siphoning. This feature greatly facilitated the study of recycling that was evaluated by selecting the reaction of $19 \mathrm{a}$ as the benchmark.

The experiments (Figure 4a) demonstrated that each of the IPB systems could promote at least five consecutive dimerization runs, still leading to the product 21a with substantial ee values. Nonetheless, some significant differences were also noted in the propensity of the diverse material to retain their initial catalytic efficiency on recycling. In particular, while the ester-type systems P1-P3 underwent a rather fast drop of performances in the successive runs $(28-33 \%$ yield, $79-83 \%$ ee in the 5th cycle; yield data not shown in Figure 4), the silyl ether materials P4 and P5 continued to provide nearly unchanged results in this short reaction series ( $45-55 \%$ yield, $94-95 \%$ ee in the 5 th cycle). 

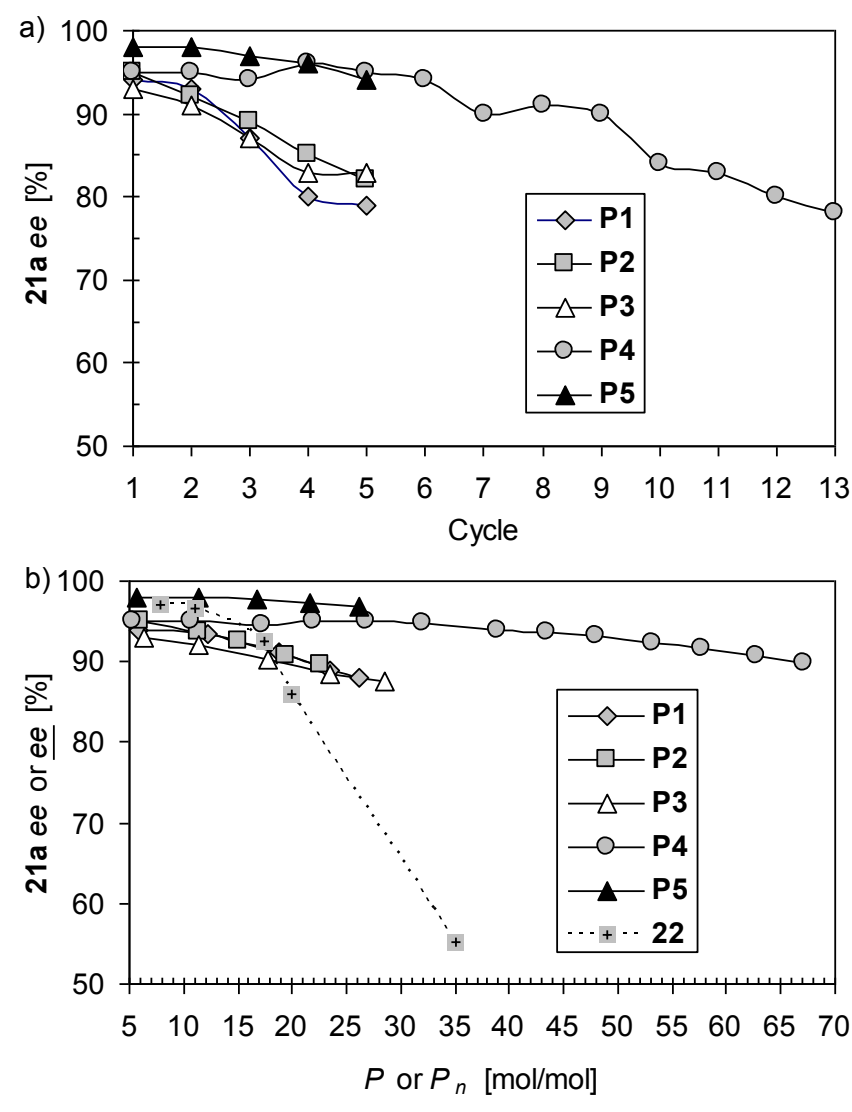

Figure 4. a) $E e$ of the product 21a in the recycle runs of P1-P5 (for the conditions, see Table $2 ; 21$ a was obtained in $28-65 \%$ isolated yield); $b$ ) Enantioselectivity $v s$. productivity for soluble (22) and IPB (P1-P5) catalysts (for the meaning of $P, P_{n}$, and $\underline{e e}$, see the text)

Because the preparation of $\mathbf{P 4}$ requires a more convenient soluble precursor than for $\mathbf{P 5}$, the former material was selected for further testing. With this aim, eight more runs were performed with the used film to give the additional data included in the Figure 4a. The results of these experiments showed that the IPB organocatalyst could be employed in thirteen successive cycles, still providing 21a in $45 \%$ isolated yield (data not shown) even in the last run. Concerning the enantioselectivity, a moderate negative trend was observed after the 6th cycle, which nevertheless did not preclude the attainment of $90-91 \%$ ee in the following three and $79 \%$ ee in the final one. ${ }^{[18]}$

Although the repeated use of $\mathbf{P 4}$ appears capable of improving the organocatalyst productivity over the analogous homogeneous systems, as discussed in the Introduction the assessment of this aspect cannot be disjoint from the concurrent evaluation of the enantioselectivity attained under alternative conditions. For this reason, the available data from the benchmark homogeneous and heterogeneous methylketene dimerization runs were converted into $P @ e e$ value pairs ${ }^{[\mathrm{gg}]}$ and, for the sake of comparison, plotted in an enantioselectivity vs. productivity $(e e-P)$ graph (Figure $4 b)$.

As far as the homogeneous reactions with $\mathbf{2 2}$ are concerned, the $P @ e e$ points were directly calculated from the catalyst amount employed in each run and the recorded yield and ee of the product 21a (Figure 3). The outcome of this analysis, shown as the broken curve in the Figure $4 \mathrm{~b}$, revealed that the use of $2.5 \mathrm{~mol} \%$ of the soluble derivative 22 could afford a result $(P \sim 11 @ 97 \%$ ee $)$, which compares favourably with that attained under standard literature conditions (e.g.P 8@97\% ee from the published data with 5 mol\% of TMS-2). ${ }^{[7 f]}$ However, due to the anticipated relationship between alkaloid amount and catalytic performances (Figure 3 ) this favourable trend did not keep valid on moving to the low-end region of catalyst loading. In this respect it is worth noting that, besides the enantioselectivity reduction, the relatively large $P$ values scored by the use of $0.1 \mathrm{~mol} \%$ of 22 (P 35@55\% ee) actually correspond to the isolation of impractically small amounts of the product 21 a ( $7 \%$ yield). Accordingly, in the reaction under exam a moderate reduction of the catalyst loading appears to be a viable option for increasing the productivity of the alkaloid derivative, which however cannot be pursued much below the 1 mol\% threshold (where P 17@93\% ee,35\% isolated yield was obtained).

The establishment of the ee- $P$ relationship for the soluble catalyst set the stage for a better assessment of the IPB materials P1-P5. For this purpose, ee and yield data of the heterogeneous runs were converted into $P_{n} @ \underline{e e}$ pairs, defined as the productivity $\left(P_{n}\right)$ and weight-averaged enantiomeric excess $(\underline{e e})$ for a virtual gross-sample of 21a obtained by ideally pooling together those isolated up to the $n$-th run (for details, see the Supporting Information).

Examination of the results shown as solid curves in the Figure $4 \mathrm{~b}$ revealed that two limiting scenarios had to be considered, depending on whether the priority was given to the maximization of the product's ee or to the catalyst's productivity. With the former choice, P5 was the only IPB system that could rival with the homogeneous catalysts across a number of reaction cycles. Even though a complete $e e-P$ analysis for the TBDMS soluble system was not performed in this work, the $P_{5} \sim 26 @ 97 \%$ ee reached with P5 (Figure 4b) appears substantially superior to $P \sim 6 @ 97 \%$ ee and $P \sim 7 @ 94 \%$ ee provided under standard conditions by the soluble derivatives 18 (Table 2, entry 5) and TBDMS-1, ${ }^{[7 f]}$ respectively.

In order to make a comparison in the alternative situation, i.e. when some reduction of the enantioselectivity was deemed acceptable, the average enantiomeric purity scored at the end of the cycles with $\mathbf{P 4}(90 \% \underline{e e})$ was arbitrarily selected as the reference level. With this choice the interpolation of the data for the soluble organocatalyst (Figure $4 \mathrm{~b}$ ) led to an estimation of $P \sim 18 @ 90 \%$ ee, corresponding to the use of $\sim 0.75 \mathrm{~mol} \%$ of 22 (see Figure 3); by contrast, the cumulative productivity of the heterogeneous system could be directly obtained as the rightmost point of the corresponding curve and was $P_{13} \sim 67 @ 90 \%$ ee .

Comparison of these results clearly demonstrated that the recycling of the IPB system P4 was capable of affording nearly three times more product than the soluble derivative $\mathbf{2 2}$ at reduced loadings, the amount of chiral organocatalyst and the enantiomeric purity of the final amide 21a being the same. Interestingly, this perhaps unimpressive $P$ increase was not the only advantage of the IPB approach because the use of the supported system also allowed to isolate the stereochemically labile product $\mathbf{2 1 a}$ in a nearly pure form, without the need of any chromatographic purification, and with a substantially higher yield $(51 \%$ overall) than with the soluble organocatalyst at low loadings ( $\sim 27 \%$ yield, see Figure 3$)$.

In the depicted scenario, the choice of immobilizing the chiral organocatalyst proved hence more effective than the mere reduction of the loading of the corresponding soluble derivative, both in terms of larger productivity of the expensive alkaloid catalyst and better use of the other chemicals involved in the catalyzed reaction. This conclusion is obviously related to the disclosed features of the reactions under exam, which include a 
reasonably good recycling profile for the IPB systems (especially P4 and P5) as well as the specific response of the homogeneous process on lowering of the catalyst loading. Because neither of the two results could be easily predicted a priori, the significance of the P@ee analysis described above should be evident. In this respect it goes to say that this kind of analysis is not expected to be an universal criterion for deciding in favour of any of the two options in a real application perspective, as many other factors (e.g. preparation simplicity and cost of either system, turnover frequency, actual product' yield, etc.) could decisively come into play. Nonetheless, in all the cases like the present one, where the chiral catalyst is the largely most expensive chemical in the transformation under study, the evaluation of the $P @ e e / P_{n} @ e$ ee relationships for the homogeneous and heterogeneous cases may be of prime importance for a fair assessment of the relative merits of the two alternatives towards process intensification. ${ }^{[19]}$

As a final comment, it is worth noting that the polystyrenesupported dimeric systems $\mathbf{1 1}$ mentioned in the Introduction appear to provide superior results than the materials P1-P5 in this study. In fact, the former IPB derivatives showed a significantly better recycling profile than the latter and allowed the attainment of significantly larger productivities, even in the high-end ee range (e.g. $P_{8} \sim 57 @ 97 \% \underline{e e}$ and $\left.P_{20} \sim 135 @ 95 \% \underline{e e}\right) \cdot{ }^{[\mathrm{g}]}$ For reasons that are unknown at present but possibly related to the different chemical stability of the linkage connecting the 9- $O$ substituent with the chiral core, for the moment the polystyrene-supported dimeric systems 11 remain therefore the reference materials for the heterogeneous catalysis of the asymmetric dimerization of ketenes.

\section{Conclusions}

In summary, a convenient procedure has been described for the covalent immobilization of different ester or silyl ether monomeric derivatives of 10,11-dihydroquinidine into cross-linked insoluble films. In spite of the rather unconventional support structure, the IPB systems obtained by this approach proved highly enantioselective and reasonably recyclable organocatalysts in the heterogeneous asymmetric dimerization of ketenes. This allowed the preparation of chiral Weinreb $\beta$-ketoamides with $79-99 \%$ ee, in the course of up to 13 reaction cycles.

Moreover, the problem of a sound comparison between IPB systems and their homogeneous counterparts has been addressed by introducing a productivity/enantioselectivity protocol that, in essence, requires the extended re-use of the recoverable catalyst, on the one hand, and the evaluation of the corresponding homogeneous system at progressively lower loadings, on the other. Because this kind of analysis allows a better critical evaluation of the results than the customary description of (a few) recycle runs alone, we feel that the proposed procedure could become a standard tool for further studies in the field of recoverable enantioselective catalysts.

Given the straightforward preparation of the alkaloid monomeric precursors 16-18 and the suitability of hydrosilylation chemistry also for the covalent anchoring of organic derivatives and catalysts within capillary channels, ${ }^{[20]}$ the extension to microfluidic devices of the approach described in this work is currently underway.

\section{Experimental Section}

For the materials, general methods, instrumentation, and analytical procedures, see the Supporting Information.

\section{Chlorodimethyl(undec-10-enyl)silane (13).}

A $100 \mathrm{~mL}$ three-necked flask fitted with a reflux condenser, dropping funnel, nitrogen inlet, and magnetic stirring bar was charged with degreased magnesium turnings $(0.716 \mathrm{~g}, 29.4 \mathrm{mmol})$, dry diethyl ether $(10 \mathrm{~mL})$, and a crystal of iodine. The flask was wrapped with a tissue cloth and a solution of 11-bromoundec-1-ene $(6.25 \mathrm{~g}, 26.8 \mathrm{mmol})$ in dry diethyl ether $(15 \mathrm{~mL})$ was added dropwise over $2 \mathrm{~h}$ to the rapidly stirred suspension, so as to maintain a slight but regular reflux in the condenser. The dropping funnel was rinsed with dry diethyl ether $(3 \mathrm{~mL})$ and the resulting mixture was left stirring overnight at r.t., to give a mid brown solution of the Grignard reagent that contained small amounts of unreacted magnesium and showed $>98 \%$ GC conversion of the starting bromide. After settling of the solid, the clear supernatant and two THF rinses $(4 \mathrm{~mL})$ were cannulated under nitrogen into a second $100 \mathrm{~mL}$ three-necked flask containing a rapidly stirred solution of dichlorodimethylsilane (6.9 mL, $57 \mathrm{mmol}, 2.1$ equiv.) in dry THF $(10 \mathrm{~mL})$. The initially clear solution was left stirring overnight at r.t. under nitrogen, to give a thick white suspension which was diluted with dry $n$-hexane $(20 \mathrm{~mL})$ and filtered under nitrogen through a mid-porosity glass frit. The residue on the frit was washed with dry $n$-hexane $(7 \times 5 \mathrm{~mL})$ and the combined filtrates were concentrated with a rotary evaporator. The crude compound was distilled under reduced pressure in a Claisen apparatus to give 13 as a clear colorless oil (b.p. $73-74^{\circ} \mathrm{C} / 0.2 \mathrm{mmHg}, 3.30 \mathrm{~g}$, $50 \%$ yield). ${ }^{1} \mathrm{H}$ NMR (300 MHz, $\left.\mathrm{CDCl}_{3}\right): \delta=0.40(\mathrm{~s}, 6 \mathrm{H}), 0.69-0.94(\mathrm{~m}$, $2 \mathrm{H}), 1.13-1.57(\mathrm{~m}, 14 \mathrm{H}), 1.90-2.17(\mathrm{~m}, 2 \mathrm{H}), 4.84-5.10(\mathrm{~m}, 2 \mathrm{H}), 5.81$ (ddt, $\left.J_{a}=16.9, J_{b}=10.2, J_{c}=6.7 \mathrm{~Hz}, 1 \mathrm{H}\right) ;{ }^{13} \mathrm{C} \mathrm{NMR}\left(75 \mathrm{MHz}, \mathrm{CDCl}_{3}\right): \delta=1.83$, $19.17,23.15,29.12,29.30,29.40,29.64,29.67,33.14,33.99,114.25$, 139.29; elemental analysis calcd (\%) for $\mathrm{C}_{13} \mathrm{H}_{27} \mathrm{ClSi}$ : C 63.24, $\mathrm{H} 11.02, \mathrm{Cl}$ 14.36, Si, 11.38; found: C 63.20, H 11.00, Cl 14.65.

\section{2-Chloro-12-methyltridec-1-ene (14).}

A solution of undec-11-en-1-ylmagnesium bromide was prepared as detailed in the previous paragraph from magnesium turnings $(0.912 \mathrm{~g}), 11$ bromoundec-1-ene $(8.00 \mathrm{~g}, 34.3 \mathrm{mmol})$, and dry diethyl ether $(10+15 \mathrm{~mL})$. After cooling externally with an ice bath, dry acetone $(3.8 \mathrm{~mL}, 52 \mathrm{mmol}$, $1.5 \mathrm{eq})$ in diethyl ether $(5 \mathrm{~mL})$ was added dropwise over $1 \mathrm{~h}$. The dropping funnel was washed with an ether rinse $(5 \mathrm{~mL})$ and, after stirring at r.t. for $15 \mathrm{~min}$, the content of the flask was hydrolyzed with satd. ammonium chloride $(25 \mathrm{~mL})$. The organic components were extracted with diethyl ether $(3 \times 10 \mathrm{~mL})$ and the combined organic phases dried over sodium sulfate. Removal of the volatiles with a rotary evaporator and then at 0.05 $\mathrm{mmHg}$ afforded crude 2-methyltridec-12-en-2-ol $(7.10 \mathrm{~g})$, as a clear paleyellow oil that was directly used in the next step.

Crude 2-methyltridec-12-en-2-ol (5.00g) was placed into a $100 \mathrm{~mL}$ twonecked flask fitted with a dropping funnel and a magnetic stirring bar. After cooling externally with an ice bath, a solution of zinc chloride (6.42 g, 47 $\mathrm{mmol})$ in $37 \% \mathrm{HCl}(6.5 \mathrm{~mL})$ was added dropwise over $40 \mathrm{~min}$, with rapid stirring. The dropping funnel was rinsed with $37 \% \mathrm{HCl}(3 \mathrm{~mL})$ and the resulting orange mixture was warmed to r.t. and kept under vigorous stirring until consumption of the alcohol substrate by GC analysis $(1 \mathrm{~h})$. The content of the flask was diluted with water $(15 \mathrm{~mL})$ and extracted with light petroleum ether $(3 \times 15 \mathrm{~mL})$. The organic phases were dried over calcium chloride and the volatiles removed with a rotary evaporator to give an oil. The crude product was purified by distillation at reduced pressure in a Claisen apparatus with a short Vigreux column. After discarding a forerun, the chloride 14 was obtained as a clear colorless oil (b.p. $106-115^{\circ} \mathrm{C} / 0.15$ $\mathrm{mmHg}, 3.45 \mathrm{~g}, 61 \%$ yield over two steps). ${ }^{1} \mathrm{H} \mathrm{NMR}\left(300 \mathrm{MHz}, \mathrm{CDCl}_{3}\right): \delta=$ $1.07-1.51(\mathrm{~m}, 14 \mathrm{H}), 1.52(\mathrm{~s}, 6 \mathrm{H}), 1.66-1.85(\mathrm{~m}, 2 \mathrm{H}), 1.88-2.16(\mathrm{~m}, 2 \mathrm{H})$, $4.76-5.16(\mathrm{~m}, 2 \mathrm{H}), 5.81$ (ddt, $\left.J_{a}=16.9, J_{b}=10.1, J_{c}=6.7 \mathrm{~Hz}, 1 \mathrm{H}\right) ;{ }^{13} \mathrm{C}$ $\mathrm{NMR}\left(50 \mathrm{MHz}, \mathrm{CDCl}_{3}\right): \delta=25.26,29.08,29.27,29.52,29.68,29.87,32.54$, $33.96,46.25,71.30,114.25,139.27$; elemental analysis calcd (\%) for $\mathrm{C}_{14} \mathrm{H}_{27} \mathrm{Cl}$ : C 72.85, H 11.79, $\mathrm{Cl} 15.36$; found: C 73.01, H 11.82, Cl 15.28. 


\section{Chlorodimethyl(2-methylpent-4-en-2-yl)silane (15).}

A $100 \mathrm{~mL}$ three-necked flask fitted with a reflux condenser, dropping funnel, nitrogen inlet, and magnetic stirring bar was charged with degreased magnesium turnings $(0.330 \mathrm{~g}, 13.7 \mathrm{mmol})$ and dry THF $(5 \mathrm{~mL})$. After the addition of 1,2-dibromoethane $(0.2 \mathrm{~mL})$ the flask was placed into an oil bath at $90^{\circ} \mathrm{C}$ and a solution of the chloride $14(2.61 \mathrm{~g}, 11.3 \mathrm{mmol})$ in dry THF $(5 \mathrm{~mL})$ was added dropwise over $2 \mathrm{~h}$. The dropping funnel was rinsed with dry THF $(3 \mathrm{~mL})$ and the resulting dark solution was kept under stirring at $70^{\circ} \mathrm{C}$ for $4 \mathrm{~h}$, whereupon $>85 \%$ conversion of the halogen substrate was observed by GC. After settling of the small amount of residual magnesium, the clear supernatant and two THF rinses $(2 \mathrm{~mL})$ were cannulated under nitrogen into a second $100 \mathrm{~mL}$ three-necked flask containing a stirred solution of dichlorodimethylsilane (1.61 g, $12.4 \mathrm{mmol}, 1.1$ equiv.) and copper cyanide (15 mg, $0.24 \mathrm{mmol}, 2 \mathrm{~mol} \%)$ in dry THF $(5 \mathrm{~mL})$. The resulting brownish clear solution was left stirring under nitrogen for $24 \mathrm{~h}$ at $70^{\circ} \mathrm{C}$. After cooling to r.t., the solution was diluted with dry $n$-hexane $(30$ $\mathrm{mL}$ ) and filtered under nitrogen through a mid-porosity glass frit. The residue on the frit was washed with dry $n$-hexane $(2 \times 5 \mathrm{~mL})$ and the combined filtrates were concentrated with a rotary evaporator. The crude compound was distilled under high vacuum in a Claisen apparatus connected with an oil diffusion pump. After discarding an abundant forerun, a fraction was collected (b.p. $40-73^{\circ} \mathrm{C} / 3-6 \cdot 10^{-5}$ mbar) that, by ${ }^{1} \mathrm{H}$ NMR and GC-ms, contained $\sim 68 \mathrm{wt} \%$ of 15 together with 12 -methyltridec-1-ene $(\sim 20$ $w t \%)$ and minor amounts $(<5 \mathrm{wt} \%)$ of 12 -methyltridec-1,12-diene and the starting chloride 14. The mixture $(1.39 \mathrm{~g}, \sim 30 \%$ yield of the title compound) was directly used in the next step. ${ }^{1} \mathrm{H}$ NMR (200 MHz, $\left.\mathrm{CDCl}_{3}\right)$ : $\delta=0.37(\mathrm{~s}, 6 \mathrm{H}), 0.96(\mathrm{~s}, 6 \mathrm{H}), 1.04-1.50(\mathrm{~m}, 16 \mathrm{H}), 1.90-2.27(\mathrm{~m}, 2 \mathrm{H}), 4.84-$ $5.19(\mathrm{~m}, 2 \mathrm{H}), 5.82\left(\mathrm{ddt}, J_{a}=16.9, J_{b}=10.1, J_{c}=6.6 \mathrm{~Hz}, 1 \mathrm{H}\right) ;{ }^{13} \mathrm{C} \mathrm{NMR}(50$ $\left.\mathrm{MHz}, \mathrm{CDCl}_{3}\right): \delta=-0.73,22.28,23.79,29.01,29.21,29.57,29.69,29.77$, $30.72,33.88,38.27,114.14,139.20 ;$ HRMS $(\mathrm{EI}+): \mathrm{m} / \mathrm{z}$ calcd for $\mathrm{C}_{16} \mathrm{H}_{33} \mathrm{ClSi}$ : 288.2040; found: 288.2047.

\section{9-O-[Dimethyl(undec-10-en-1-yl)silyl]-10,11-dihydroquinidine (17).}

A $10 \mathrm{~mL}$ Schlenk tube was charged under nitrogen with hydroquinidine $(0.250 \mathrm{~g}, 0.766 \mathrm{mmol})$, dry DMF $(1.0 \mathrm{~mL})$, triethylamine $(0.21 \mathrm{~mL}, 1.5$ $\mathrm{mmol}$ ), 4-dimethylaminopyridine ( $30 \mathrm{mg}, 0.25 \mathrm{mmol}, 30 \mathrm{~mol} \%$ ), and the chlorosilane 13 ( $0.28 \mathrm{~g}, 1.0 \mathrm{mmol}, 1.3 \mathrm{eq})$. The resulting mixture was magnetically stirred at r.t. for $48 \mathrm{~h}$ and then diluted with toluene $(5 \mathrm{~mL})$. The organic phases were washed with water $(2 \times 5 \mathrm{~mL})$ and dried over anhydrous sodium sulfate. The volatiles were removed with a rotary evaporator and the residue was purified by flash chromatography $\left(\mathrm{SiO}_{2}\right.$, AcOEt : $\mathrm{MeOH}=95: 5)$ to give $\mathbf{1 7}(0.255 \mathrm{~g}, 62 \%$ yield $)$ as a pale-yellow viscous oil. TLC $R_{f}=0.51\left(\mathrm{SiO}_{2}, \mathrm{AcOEt}: \mathrm{MeOH} 95: 5\right) ;[\alpha]_{\mathrm{D}}{ }^{21}=+1.1(\mathrm{c}=$ $\left.0.51 \mathrm{~g} / 100 \mathrm{~mL}, \mathrm{CH}_{2} \mathrm{Cl}_{2}\right)$; $\mathrm{MS}(\mathrm{ES}+): m / z+537.8\left(\mathrm{M}+\mathrm{H}^{+}\right) ;{ }^{1} \mathrm{H}$ NMR $(200$ $\left.\mathrm{MHz}, \mathrm{CDCl}_{3}\right): \delta=-0.03(\mathrm{~s}, 3 \mathrm{H}), 0.08(\mathrm{~s}, 3 \mathrm{H}), 0.53-0.55(\mathrm{~m}, 2 \mathrm{H}), 0.90(\mathrm{t}, J=$ $7.1 \mathrm{~Hz}, 3 \mathrm{H}), 1.10-1.75(\mathrm{~m}, 14 \mathrm{H}), 1.98-2.08(\mathrm{~m}, 2 \mathrm{H}), 2.68-2.98(\mathrm{~m}, 4 \mathrm{H})$, 3.08-3.22 (m, 1H), $3.94(\mathrm{~s}, 3 \mathrm{H}), 4.86-5.02(\mathrm{~m}, 2 \mathrm{H}), 5.68-5.89(\mathrm{~m}, 2 \mathrm{H}), 7.22$ (br. s, $1 \mathrm{H}), 7.34$ (dd, $\left.J_{a}=9.2, J_{b}=2.5 \mathrm{~Hz}, 1 \mathrm{H}\right), 7.51$ (br. s, $\left.1 \mathrm{H}\right), 7.99$ (d, $J=$ $9.0 \mathrm{~Hz}, 1 \mathrm{H}), 8.71(\mathrm{~d}, J=4.4 \mathrm{~Hz}, 1 \mathrm{H}) ;{ }^{13} \mathrm{C} \mathrm{NMR}\left(50 \mathrm{MHz}, \mathrm{CDCl}_{3}\right): \delta=-1.45$ $12.08,16.93,19.69,23.26,25.32,26.47,27.16,29.53,29.57,33.50,33.87$, $37.46,50.55,51.12,55.96,60.66,73.06,100.64,114.15,118.70,121.79$, $126.24,131.87,139.26,144.50,147.42,147.65,158.11$; elemental analysis calcd (\%) for $\mathrm{C}_{33} \mathrm{H}_{52} \mathrm{~N}_{2} \mathrm{O}_{2} \mathrm{Si}$ : C 73.83, H 9.76, N 5.22, O 5.96, Si 5.23, found: C 73.40, H 9.62, N 5.17.

\section{9-O-[Dimethyl(2-methyltridec-12-en-2-yl)silyl]-10,11-dihydroquinidine} (18).

A $10 \mathrm{~mL}$ Schlenk tube was charged under nitrogen with hydroquinidine $(0.430 \mathrm{~g}, 1.32 \mathrm{mmol})$, dry DMF $(1.0 \mathrm{~mL})$, triethylamine $(0.83 \mathrm{~mL}, 6.0$ $\mathrm{mmol}$ ), 4-dimethylaminopyridine (16 $\mathrm{mg}, 0.13 \mathrm{mmol}, 10 \mathrm{~mol} \%$ ), and the chlorosilane 15 ( $0.66 \mathrm{~g}, 68 \%$ purity, $\sim 1.5 \mathrm{mmol}, 1.1 \mathrm{eq})$. The resulting mixture was magnetically stirred at r.t. for $72 \mathrm{~h}$ and then diluted with toluene $(5 \mathrm{~mL})$. The organic phases were washed with water $(2 \times 5 \mathrm{~mL})$ and dried over sodium sulfate. The volatiles were removed with a rotary evaporator and the residue was purified by flash chromatography $\left(\mathrm{SiO}_{2}\right.$, AcOEt $: \mathrm{MeOH}=95: 5)$ to give $\mathbf{1 8}(0.406 \mathrm{~g}, 53 \%$ yield $)$ as a pale-yellow viscous oil. TLC $R_{f}=0.59\left(\mathrm{SiO}_{2}, \mathrm{AcOEt}: \mathrm{MeOH} 95: 5\right) ;[\alpha]_{\mathrm{D}}{ }^{21}=+1.0(\mathrm{c}=$ $\left.0.53 \mathrm{~g} / 100 \mathrm{~mL}, \mathrm{CHCl}_{3}\right) ; \mathrm{MS}(\mathrm{ES}+): m / z+579.9\left(\mathrm{M}+\mathrm{H}^{+}\right) ;{ }^{1} \mathrm{H}$ NMR $(600$ $\left.\mathrm{MHz}, \mathrm{CDCl}_{3}\right)$ : $\delta$ (major rotamer, $\left.\sim 76 \%\right)=-0.33(\mathrm{~s}, 3 \mathrm{H}), 0.15(\mathrm{~s}, 3 \mathrm{H}), 0.90(\mathrm{t}$, $J=7.4 \mathrm{~Hz}, 3 \mathrm{H}), 0.92$ (s, 3H), 0.94 (s, 3H), 0.99-1.58 (m, 21H), 1.64 (br. s, $1 \mathrm{H}), 1.72(\mathrm{~m}, 1 \mathrm{H}), 1.92-2.10(\mathrm{~m}, 3 \mathrm{H}), 2.65-2.75(\mathrm{~m}, 1 \mathrm{H}), 2.76-2.94(\mathrm{~m}$, $3 \mathrm{H}), 2.96-3.03(\mathrm{~m}, 1 \mathrm{H}), 3.94(\mathrm{~s}, 3 \mathrm{H}), 4.89-5.02(\mathrm{~m}, 2 \mathrm{H}), 5.60(\mathrm{~d}, J=3.1$ $\mathrm{Hz}, 1 \mathrm{H}$ ), 5.81 (ddt, $\left.J_{a}=16.9, J_{b}=10.2, J_{c}=6.7 \mathrm{~Hz}, 1 \mathrm{H}\right), 7.19$ (d, $J=2.4$ $\mathrm{Hz}, 1 \mathrm{H}), 7.36\left(\mathrm{dd}, J_{a}=9.2, J_{b}=2.6 \mathrm{~Hz}, 1 \mathrm{H}\right), 7.55(\mathrm{~d}, J=4.5 \mathrm{~Hz}, 1 \mathrm{H}), 8.02$ $(\mathrm{d}, J=9.2 \mathrm{~Hz}, 1 \mathrm{H}), 8.73(\mathrm{~d}, J=4.5 \mathrm{~Hz}, 1 \mathrm{H}) ; \delta($ minor rotamer, $\sim 24 \%)=$ $0.42(\mathrm{~s}, 3 \mathrm{H}), 0.11(\mathrm{~s}, 3 \mathrm{H}), 0.80(\mathrm{~s}, 3 \mathrm{H}), 0.82(\mathrm{~s}, 3 \mathrm{H}) 2.45-2.53(\mathrm{~m}, 2 \mathrm{H})$, 2.55-2.64 (m, 1H), 3.35-3.49 (m, 1H), $3.92(\mathrm{~s}, 3 \mathrm{H}), 4.80(\mathrm{~d}, J=9.2 \mathrm{~Hz}$, $1 \mathrm{H}), 7.10(\mathrm{~d}, J=4.3 \mathrm{~Hz}, 1 \mathrm{H}), 7.32\left(\mathrm{dd}, J_{a}=9.2, J_{b}=2.7 \mathrm{~Hz}, 1 \mathrm{H}\right), 7.86(\mathrm{~d}, J$ $=2.7 \mathrm{~Hz}, 1 \mathrm{H}), 7.98(\mathrm{~d}, J=9.2 \mathrm{~Hz}, 1 \mathrm{H}), 8.64(\mathrm{~d}, J=4.2 \mathrm{~Hz}, 1 \mathrm{H}) ;{ }^{13} \mathrm{C}-\mathrm{NMR}$ $\left(50 \mathrm{MHz}, \mathrm{CDCl}_{3}\right): \delta($ major + minor rotamer $)=-4.29,-4.05,-3.89,-3.75$, $12.18,20.65,21.23,21.40,22.86,22.91,23.81,23.98,25.28,25.88,26.24$, $26.31,26.62,27.29,27.56,29.04,29.26,29.62,29.79,29.85,30.89,33.92$, $37.71,38.76,38.86,49.62,49.92,50.55,51.49,55.45,55.80,61.05,61.15$, $73.15,79.64,100.51,105.00,114.19,119.03,121.26,121.41,121.67$, $126.40,127.13,131.53,131.95,139.30,144.40,145.53,147.46,147.59$, 148.42, 156.57, 157.96; elemental analysis calcd (\%) for $\mathrm{C}_{36} \mathrm{H}_{58} \mathrm{~N}_{2} \mathrm{O}_{2} \mathrm{Si} \cdot 0.02 \mathrm{CH}_{2} \mathrm{Cl}_{2}$ : C 74.51, H 10.07, Cl 0.24, N 4.82, O 5.51, Si 4.84; found: C 74.59, H 10.15, N 4.81.

\section{Preparation of P1-P5 by anchoring 16-18 into cross-linked silicone} films. General procedure.

A solution of the unsaturated alkaloid derivative 16, 17, or $18(0.40-0.75$ mmol), PMHS, PDMS-DV lw, and PDMS-DV hw (for the exact ratios, see Table 1) in toluene (14-20 mL) was poured into a flat PTFE-lined vessel (90-150 $\mathrm{cm}^{2}$ bottom area). A $1.0 \mathrm{mM}$ solution of the Karstedt catalyst in toluene (molar ratio $\mathrm{SiH} / \mathrm{Pt}=1000$ ) was evenly added drop by drop and, after swirling to complete the mixing of the solutions, the vessel was covered with a glass lid and heated under air for $1 \mathrm{~h}$, on a plate set at $50^{\circ} \mathrm{C}$. The temperature was then raised to $70^{\circ} \mathrm{C}$ to effect the solvent evaporation and polymer cross-linking. After overnight curing, the resulting solid film was swollen with a solution of 1-hexadecene $(0.10 \mathrm{~mL})$ in toluene $(10 \mathrm{~mL})$ and the volatiles were evaporated again by gently heating for $1 \mathrm{~h}$ at $70^{\circ} \mathrm{C}$. The polymer film was moistened with little THF to facilitate the detachment from the vessel and transferred to a metal-net thimble, which was placed into a Kumagawa device. After continuous extraction over 2 days, first with dry THF and then with dry $\mathrm{CH}_{2} \mathrm{Cl}_{2}$, the almost colourless and nearly transparent material P1-P5 (Figure S1) was dried under reduced pressure $(0.05 \mathrm{mmHg})$ Callipers measurement of the resulting soft, elastic films indicated an approximate thickness of $0.2 \mathrm{~mm}$. The material was characterized by IR (Figure S2) and elemental analysis. Elemental analysis found (N\%): P1 0.77, P2 0.53, P3 1.59, P4 0.66, P5 0.73.

\section{Heterogeneous catalytic asymmetric ketene dimerization. General procedure.}

A $50 \mathrm{~mL}$ Schlenk tube, provided with a magnetic follower and stopcock side arm, was charged under nitrogen with P1-P5 (88-263 mg, corresponding $0.050 \mathrm{mmol}, 5 \mathrm{~mol} \%$, of the supported alkaloid derivative). After sealing the tube with a septum, dry $\mathrm{CH}_{2} \mathrm{Cl}_{2}(10 \mathrm{~mL})$ was syringed into the tube and the polymer film allowed to swell by stirring for $5 \mathrm{~min} . \mathrm{N}, \mathrm{N}$ Diisopropylethylamine $(170 \mu \mathrm{L}, 1.0 \mathrm{mmol})$ and acid chloride 19a-c $(1.0$ $\mathrm{mmol})$ were sequentially injected through the septum and the mixture was set stirring at $500 \mathrm{rpm}$ at r.t. After the time $t_{l}$ (Table 2), the clear supernatant was cannulated under nitrogen into a dry Schlenk tube and the polymer film washed with $\mathrm{CH}_{2} \mathrm{Cl}_{2}(5 \mathrm{~mL})$. The combined organic phases were treated with $\mathrm{HN}(\mathrm{OMe}) \mathrm{Me}(37 \mu \mathrm{L}, 0.50 \mathrm{mmol})$ and 2-pyridone (4.7 $\mathrm{mg}, 0.05 \mathrm{mmol})$ and the resulting solution was stirred at room temperature 
for the time $t_{2}$ (Table 2). For the ee determination, a sample of the reaction mixture $(0.20 \mathrm{~mL})$ was passed through small pad of silica gel with $n$ hexane : AcOEt $=2: 1(3 \times 1 \mathrm{~mL})$, evaporated with a nitrogen flow and dissolved in 2-propanol for HPLC analysis. ${ }^{[5 \mathrm{~g}, 7 \mathrm{f}]}$ The remaining of the solution was washed with concentrated $\mathrm{pH} 7$ buffer solution, ${ }^{[7 \mathrm{f}]}$ dried $\left(\mathrm{Na}_{2} \mathrm{SO}_{4}\right)$, and evaporated to give the Weinreb amides 21a-c as turbid oils that were nearly pure by ${ }^{1} \mathrm{H}$ NMR (Figure S3). The polymeric film recovered after cannulation was washed with dry $\mathrm{CH}_{2} \mathrm{Cl}_{2}(2 \times 1 \mathrm{~mL})$ and then directly used in further catalysis cycles.

Supporting Information (see footnote on the first page of this article): Procedure for the homogeneous catalysis runs, spectra of the new compounds, appearance and IR of the polymer films, and elaboration of the P/ee data.

\section{Acknowledgments}

Work supported by the University of Pisa, MIUR (Project "Sintesi e Stereocontrollo di Molecole Organiche per lo Sviluppo di Metodologie Innovative di Interesse Applicativo - PRIN 2007”) and ICCOM-CNR.

[1] a) Chiral Catalyst Immobilization and Recycling (Eds.: D. E. De Vos, I. F. J. Vankelecom, P. A. Jacobs), Wiley-VCH, Weinheim 2000; b) Q.-H. Fan, Y.-M. Li, A. S. C. Chan, Chem. Rev. 2002, 102, 3385-3466; c) M. Benaglia, A. Puglisi, F. Cozzi, Chem. Rev. 2003, 103, 3401-3429; d) F. Cozzi, Adv. Synth. Catal. 2006 348, 1367-1390; e) M. Benaglia, New J. Chem. 2006, 30, 1525 1533; f) A. F. Trindade, P. M. P. Gois, C. A. M. Afonso, Chem. Rev. 2009, 109, 418-514; g) J. Lu, P. H. Toy, Chem. Rev. 2009, 109, 815-838; h) T. E. Kristensen, T. Hansen, Eur. J. Org. Chem 2010, 3179-3204; i) Heterogenized Homogeneous Catalysts for Fine Chemicals Production, Vol. 33 (Eds.: P. Barbaro, F. Liguori), Springer Netherlands, Dordrecht, 2010; j) Catalytic Methods in Asymmetric Synthesis (Eds.: E. Gruttadauria, F. Giacalone), John Wiley \& Sons, Inc., 2011.

[2] a) O. Gleeson, R. Tekoriute, Y. K. Gun'ko, S. J. Connon, Chem.-Eur. J. 2009, 15, 5669-5673; b) C. W. Jones, Top. Catal. 2010 , $53,942-952$.

[3] A. Mandoli, D. Pini, M. Fiori, P. Salvadori, Eur. J. Org. Chem. 2005, 1271-1282.

[4] a) K. Kacprzak, J. Gawronski, Synthesis 2001, 961-998; b) C. Palomo, M. Oiarbide, R. Lopez, Chem. Soc. Rev. 2009, 38, 632653 ; c) T. Marcelli, H. Hiemstra, Synthesis 2010, 2010, 1229,1279

[5] a) C. E. Song, J. W. Yang, H.-J. Ha, Tetrahedron: Asymm. 1997, 8, 841-844; b) C. Bolm, A. Maischak, Synlett 2001, 93-95; c) F. Bigi, S. Carloni, R. Maggi, A. Mazzacani, G. Sartori, G. Tanzi, J. Mol. Catal. A: Chem. 2002, 182-183, 533-539; d) S. France, D. Bernstein, A. Weatherwax, T. Lectka, Org. Lett. 2005, 7, 3009-3012; e) B. Thierry, J.-C. Plaquevent, D. Cahard, Mol. Diversity 2005, 9, 277-290; f) R. Chinchilla, C. Najera, F. J. Ortega, S. Tari, Tetrahedron: Asymm. 2009, 20, 2279-2286; g) R. P. Jumde, A. Mandoli, F. De Lorenzi, D. Pini, P. Salvadori, Adv. Synth. Catal. 2010, 352, 1434-1440.

[6] K. M. Kacprzak, N. M. Maier, W. Lindner, Tetrahedron Lett. 2006, 47, 8721-8726.

[7] a) M. A. Calter, J. Org. Chem. 1996, 61, 8006-8007; b) M. A. Calter, X. Guo, J. Org. Chem. 1998, 63, 5308-5309; c) M. A.
Calter, F. C. Bi, Org. Lett. 2000, 2, 1529-1531; d) M. A. Calter, X. Guo, W. Liao, Org. Lett. 2001, 3, 1499-1501; e) M. A. Calter, X. Guo, Tetrahedron 2002, 58, 7093-7100; f) M. A. Calter, R. K. Orr, W. Song, Org. Lett. 2003, 5, 4745-4748.

[8] A. Mandoli, M. Lessi, D. Pini, C. Evangelisti, P. Salvadori, Adv. Synth. Catal. 2008, 350, 375-379.

[9] Y. Motoyama, T. Nishikata, H. Nagashima, Chem.--Asian J. 2011, 6, 78-82.

[10] a) M. S. DeClue, J. S. Siegel, Org. Biomol. Chem. 2004, 2, 2287-2298; b) M. A. Grunlan, K. R. Regan, D. E. Bergbreiter, Chem. Commun. 2006, 1715-1717.

[11] a) A. Shirahata, Tetrahedron Lett. 1989, 30, 6393-6394; b) C. G. L. Khoo, J. B. Lando, H. Ishida, J. Polym. Sci., Part B: Polym. Phys. 1990, 28, 213-232.

[12] a) S. J. Rowan, J. K. M. Sanders, J. Org. Chem. 1998, 63, 15361546; b) S. J. Rowan, D. J. Reynolds, J. K. M. Sanders, J. Org. Chem. 1999, 64, 5804-5814.

[13] M. Butts, J. Cella, C. D. Wood, G. Gillette, R. Kerboua, J. Leman, L. Lewis, S. Rubinsztajn, F. Schattenmann, J. Stein, D. Wicht, S. Rajaraman, J. Wengrovius, in Kirk-Othmer Encyclopedia of Chemical Technology (5th Edition), Vol. 22, 2006, pp. 547-626.

[14] B. P. S. Chauhan, J. S. Rathore, J. Am. Chem. Soc. 2005, 127, 13738-13738.

[15] J. Y. Corey, Adv. Organomet. Chem. 2004, 51, 1-52.

[16] P. L. Launer, in Silicone Compounds Register and Review (Ed.: B. Arkles), Petrarch Systems, Inc., Bristol, PA, 1987available at http://www.gelest.com/Library/11Infra.pdf (access effected on Jun, 1st 2011).

[17] a) L. Mink, Z. Ma, R. A. Olsen, J. N. James, D. S. Sholl, L. J. Mueller, F. Zaera, Top. Catal. 2008, 48, 120-127; b) J. Lai, Z. Ma, L. Mink, L. J. Mueller, F. Zaera, J. Phys. Chem. B 2009, 113, 11696-11701.

[18] In response to a referee query, it has be noted that rapid magnetic stirring caused some breaking of the polymer films into smaller particles. Even in the last cycle this problem did not prevent, however, the rapid separation of the reaction mixture by siphoning.

[19] For the sake of completeness, it should be noted that Calter and co-workers described conditions for the homogeneous dimerization which provide up to $\mathrm{P} \sim 92 @ 99 \%$ ee (Ref. 7d). However, these protocols require the external generation of methylketene and the use of low temperatures $\left(-78^{\circ} \mathrm{C}\right)$ and are, therefore, less convenient than the alternative procedure also followed in this work.

[20] a) O. Trapp, S. K. Weber, S. Bauch, W. Hofstadt, Angew. Chem., Int. Ed. 2007, 46, 7307-7310; b) D. Wistuba, V. Schurig, $L C$ GC Eur. 2009, 22, 60-69; c) S. K. Weber, S. Bremer, O. Trapp, Chem. Eng. Sci. 2010, 65, 2410-2416.

Received: ((will be filled in by the editorial staff)) Published online: ((will be filled in by the editorial staff)) 
A series of hydroquinidine derivatives embedded into elastomeric silicone films were prepared and used as insoluble organocatalysts in the asymmetric dimerization of ketenes. A protocol was also introduced for comparing the productivity/enantioselectivity performances of the supported catalyst with those of the analogous soluble counterparts.

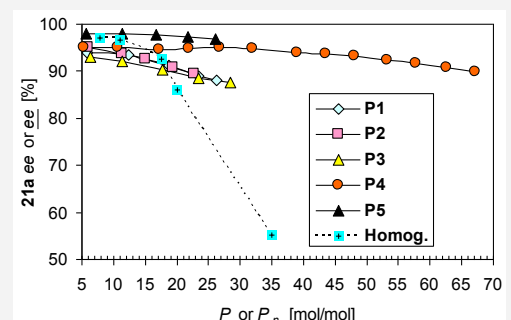

Damiano Cancogni, Alessandro Mandoli,* Ravindra P. Jumde, and Dario Pini. Page No. - Page No.

Silicone-supported Cinchona alkaloid derivatives as insoluble organocatalysts in the enantioselective dimerization of ketenes.

Keywords: Asymmetric Catalysis / Cinchona Alkaloids / Ketene Dimerization / Organocatalysis / Silicones / Supported Catalysts 
